\title{
Impact of UVB Solar Radiation on Ambient Temperature for Kuwait Desert Climate
}

\author{
Ibrahim M. Kadad', Kandil M. Kandil ${ }^{*}$, Talal H. Alzanki² \\ ${ }^{1}$ Public Authority for Applied Education and Training (PAAET), Applied Sciences Department, College of Technological \\ Studies, Shuwaikh, Kuwait \\ ${ }^{2}$ Public Authority for Applied Education and Training (PAAET), Electronic Engineering Department, College of Technological \\ Studies, Shuwaikh, Kuwait \\ Email: *km.kandil@paaet.edu.kw
}

How to cite this paper: Kadad, I.M., Kandil, K.M. and Alzanki, T.H. (2020) Impact of UVB Solar Radiation on Ambient Temperature for Kuwait Desert Climate. Smart Grid and Renewable Energy, 11, 103-125. https://doi.org/10.4236/sgre.2020.118008

Received: February 7, 2020

Accepted: August 25, 2020

Published: August 28, 2020

Copyright $\odot 2020$ by author(s) and Scientific Research Publishing Inc. This work is licensed under the Creative Commons Attribution International License (CC BY 4.0).

http://creativecommons.org/licenses/by/4.0/ (c) (i) Open Access

\begin{abstract}
This study examines the correlation between solar UVB and different weather parameters in Kuwait climate. To achieve that purpose, an experimental outdoor facility is designed and set up at the College of Technological Studies, Kuwait for regular monitoring of solar global radiation, UVB radiation and ambient temperature in Kuwait from beginning of January $1^{\text {st }} 2014$ until the end of December 2019. Outcomes reveal that the change of solar UVB as well as global radiation through the whole day inaugurate the same behavior for the recorded data in clear day times. Statistical analysis is carried out to obtain a correlation linking UVB radiation and both ambient temperature and global solar radiation. Regression analysis of the current work shows that there is a solid correlation among UVB radiation and both ambient temperature and global solar radiation, especially for intermediate to small global solar radiation ranges. In addition, UV index is evaluated for various months at all day times. It is important to record that UV index with the maximum values is attained in May-August months through midday period. Also, UV index values do not surpass the accepted extreme value which is higher than 9 during any time of the study period.
\end{abstract}

\section{Keywords}

Ambient Temperature, UVB Radiation, Solar Radiation, UV Index, Relative Humidity

\section{Introduction}

In past years, there is an increasing attention to examine solar ultraviolet (UV) radiation because of its obvious impact on global warming as well as the decrease in stratospheric ozone. Ultraviolet radiation increase has a significant impact on 
different biological and chemical processes. Most people are exposed to UV radiation daily for a certain hour and this exposure is good for obtaining vitamin $\mathrm{D}$ for our skin. However, excess exposure to UV radiation is harmful and can cause skin cancer. Therefore, information regarding received UV radiation is a substantial knowledge for many fields of research as tropospheric chemistry, oceanography, forestry and cancer research. In addition, developments in industry have generated CFCs reacting with stratospheric ozone, which protects us from harmful wavelengths of UV radiation.

Solar radiation reaching Earth are typically categorized in various wavelengths values. Ultraviolet (UV) radiation wavelength is the fraction of solar radiation with the shortest wavelengths. Solar UV is generally divided into three parts: UVA having the range $320-400 \mathrm{~nm}$, UVB with the range $280-320 \mathrm{~nm}$ and UVC with $200-280 \mathrm{~nm}$. UVB radiation is regarded as the most effective in UV range and it causes sunburn and tanning in addition to its effect on the immune system. UVB solar radiation represents about $1.3 \%$ of the whole solar spectrum and it has a great impact on chemical and biological processes. The amount of solar UVB radiation reaches the earth depends on location characteristics and time of the year. Analyzing these parameters enable us to estimate UV values in different locations. Long time disclosure to UV results in a dangerous consequence on eyes, degeneration of the macula in addition to the weakness in the immune system [1] [2] [3] [4] [5].

Recently, many researchers paid a great attention to the analysis of the UV radiation [6]-[11] because of the harmful biological and physical effects resulting from direct exposure to this radiation. Fountoulakis et al. [12] utilized long-term spectral UVB measurements of the solar radiation over different countries for a period of twenty-five years. They showed that the measurements for long term UVB, which achieves the earth's surface changes significantly awing to the location. The main reasons of these changes are variations in aerosols and ozone. On the other hand, for higher latitudes, the variations are mainly due to surface reflectivity and clouds. They concluded that more research is needed to correlate UVB radiation to geophysical variables.

Andrady et al. [13] examined the impact of solar UVB and climate change on material degradation. They revealed that change in climate parameters like temperature and moisture produced from UVB exposure could greatly affect material degradation. So, more research is required to identify the synergetic changes of these factors on material damage. Ultraviolet solar intensity at different times is measured by Elani [14] Riyadh, Saudi Arabia. He introduced theoretical formula resulted from comparing recorded measurements and the corresponding theoretical data. He stated that the environmental factors help to better analyze UV reflection, UV scattering and ozone layers in the studied location. A number of researchers presented different equations relating UV and global radiation in previous years based on measurements from Valencia [15], Dharan [16], Granada [17], Postdam [18], Edmonton [19] and Malta [20]. The mentioned studies have examined UV characteristics recorded in specific site. 
Different measurements facilities are installed by Leal et al. [21] for continuous daily UV and global radiation monitoring. They introduced statistical models to utilize daily global radiation to determine daily UV radiation. The proposed statistical equations have a good accuracy, so proposed models can be utilized for the calculation of UV radiation in locations whereas this radiation cannot be measured. Al-Mostafa et al. [22] examined the effect of stratospheric ozone and aerosol at different six locations in Saudi Arabia. They carried out detailed satellite monitoring of the atmosphere during the time from 979-2005. They stated that although reduction of stratospheric Ozone, Erythemal ultraviolet radiation (EUV) decreases in summer because of the rise in the aerosol at summer.

The stratospheric ozone depletion effects on UV strength at earth are investigated by Blais et al. [23]. In addition, other than ozone factors are studied. The parameters (clouds, aerosols and surface reflectivity) with significant effect on short and long terms UV variations are examined. They used their measurements to calculate variations in UV radiation up to $21^{\text {th }}$ century ending. Yousif et al. [24] performed UVB radiation measurements at Valladolid University, Spain where the weather is warm in summer due wind velocity trend over Atlantic Ocean. The UV radiation rate in Mashhad, Iran is determined by Akhlaghi et al. [25]. The results indicate that the average rate of UV in Mashhad is lower than $10 \mathrm{~W} / \mathrm{m}^{2}$, which is the standard global.

El-Nouby [26] introduced a correlation to determine daily total UVB in a subtropical region in Upper Egypt. Stammes et al. [27] proposed theoretical method of the former type to calculate UV radiation. It should be noted that models verification necessitates precise spectral measurements in addition to continuous monitoring of environmental conditions influencing the solar spectrum for different wavelengths. Further, these theoretical techniques are very complicated. Even though there are several stations monitoring broad band UV radiation, a very few lengthy times of measured parameters have been introduced in literature.

Escobedo et al. [28] examined the variations of UV, photo synthetically active and near IR parts. Results are adapted to obtain the portions of spectral parts to global radiation. Calibrated data showed that suggested models precisely determine the flux of spectral radiation. UV radiation monitoring for flat and sloped planes surfaces located in Spain are examined by Navntoft et al. [29]. Average ratio of horizontal to oriented UV irradiation is 0.95 and 1.25 for both winter and summer. Corresponding values in total spectra increases to 0.85 and 1.70.

Jacovides et al. [30] introduced the results of solar UV radiation obtained carried out by his students employing monitoring-networks. Records of UVA, UVB fluxes of broadband radiation are utilized to study the correlation among radiant fluxes at different locations. Measured data indicated that the relation between total UV radiation and global radiation is linear while, the correlation between global and UVB radiation is a quadratic relation. Also, an inverse correlation is detected between the ratio UVB/G and ozone amount for Acropolis location. This behavior may be related to changes of different atmospheric factors other than ozone column. Koronakis et al. [31] presented the ratio between global and 
UV radiation in Mediterranean area; their results indicated an annual $4.1 \%$ in Athens, Greece.

Kudsih et al. [32] concluded that ozone in UV and water vapor in IR solar spectrum band are responsible for solar radiation in the atmosphere. They proposed a relation to evaluate UVB radiation flux in terms of optical path length and global radiation. Furthermore, a parametric sensitivity analysis was carried out the empirical relation utilizing two various methods. Kudsih et al. [33] introduced a relation between global, global and diffuse radiation in terms of relative optical air mass and UVB optical depth. The records of the components of direct and global UVB allowed the evaluation of atmospheric optical depth. So, the incident UVB radiation is introduced correlated to the optical depth and relative air mass utilizing an updated formula of the law of Lambert-Beer. The relations of both global and direct UVB portions are calibrated versus measurements. Moreover, results attained from suggested models predicted reliable results for different UVB parts.

It is noticed that for Dead Sea, the values of monthly mean UV Index never exceeded the risky range. In addition, a linear correlation exists among UV and total solar radiation, especially for the range of low to moderate global radiation [34]. Downs et al. [35] introduced two different mathematical models to determine the UV index at different locations for better understanding the physical phenomena that impact the value of UV index. They concluded that in high altitude sites of tropical South America, UV index could attain extreme values of 18. In the other hand, the value of UV index can exceed 10 in tropical latitude during summer. So, they advised public awareness for protection as well as avoidance of solar energy exposure at these locations. Charuchittipan [36] et al. developed an empirical correlation to calculate diffuse NIR radiation using ground-based measurements and satellite as input. Diffuse NIR is found to be best modelled employing the three mentioned parameters as independent parameters for an exponential relation. They stated that the semi empirical model agrees well with diffuse NIR data. Ye et al. [37] adapted a solar selective absorber to investigate solar selective absorber with different polarization angles. The introduced configuration has a spectral range of $300 \mathrm{~nm}$ to $1777 \mathrm{~nm}$. The suggested shape can attain a wide absorption band like free space impedance. Furthermore, a full wave simulation is carried out to examine the influence of geometric configuration. Thermal efficiency evaluated can attain higher values as $92.23 \%$ at $373.15 \mathrm{~K}$. Results reveal that there is a great need for solar thermal applications with the proposed configuration.

The main aim of this work is to set up a mathematical correlation correlating UVB radiation to total solar radiation and ambient temperature in Kuwait climate. Predicted correlation can be utilized to determine UVB radiation at any location in Kuwait where UVB records are not available utilizing measurements of global radiation and ambient temperature for these locations. A test station is setup at the College of Technological Studies, Kuwait to monitor UVB radiation, global radiation and ambient temperature. Measurements are performed from beginning of January 2014 until the end of December 2019. In addition, the 
second goal of this work is to calculate ultraviolet index (UVI) all over the studied period. Ultraviolet index (UVI) is an indicator of the strength of sunburn, which resulted from exposure to UV radiation at a certain location and time. The largest UVI index value means the larger risk for skin and eye damage and consequently harm occurs in shorter times. Information about this index help people to protect themselves from UV radiation.

\section{Experimental Setup}

The measurement station has the devices necessary for continuous recoding of UVB radiation on horizontal plane, global radiation (G) and surrounding temperature. UVB Biometer Model 501 is employed to record UVB radiation received by a horizontal surface. UVB Biometer is utilized to record UVB radiation (280 $320 \mathrm{~nm}$ ). Biometer position is selected so that no shadow overcast into the Biometer through the measurement time.

UV irradiation biological effect is expressed in MED/h (Minimum Erythema Dose per Hour). One MED/h will result in a minimum redness in skin after exposure to radiation in $1[\mathrm{MED} / \mathrm{h}]=5.83 \times 10^{-6}\left[\mathrm{~W} / \mathrm{cm}^{2}\right]$ of Effective Power for an MED of $21 \mathrm{~mJ}$ per $\mathrm{cm}^{2}$ effective dose. Calibration of detector is carried out in a clear sky at ambient temperature $25^{\circ} \mathrm{C}$ for $30^{\circ}$ solar zenith angle.

The concept of UVB radiation measurement is as follows; solar radiation passes from input filters to enhance the detector cosine response. Then light filtered which includes all UV spectrum, energies the phosphor. GaAs diode detects visible light emitted from phosphor. Both the phosphor and the diode are maintained in the metal compound by the Peltier element. The UVB Biometer is compact and has a spectral response close to erythema. It has menu to organize different options, recorder keypad and alphanumeric LCD. To ensure precise monitoring of UVB radiation, the detector should be fixed correctly. The detector is manufactured for different, but the recorder operates at room conditions only. To get precise records most of sky must be viewed by position of the detector and the detector must be far from dust as dust leads to significant variation of the UVB radiation received by the detector.

Eppley Precision Spectral Pyranometers (PSP) is employed to record global radiation received by horizontal surface. PSP pyranometer employ a thermopile detector to measure solar radiation. Temperature sensors accuracy changes awing to the objective needed. The accuracy of ambient temperature measurements is $\pm 0.1^{\circ} \mathrm{C}$. Ambient temperature is monitored employing standard resistance thermometer (RTD-PT100) to ensure high accuracy.

All instruments outputs are linked to data taker (Model DT80) which is a precise data acquisition system to record all the required parameters accurately. Data Taker adapted has a variety of options permitting its use in different measurements. Dual channel concept of Data Taker enables using 15 common analog inputs. It has different sensors including resistance thermometer detectors (RTDs), different types of thermocouples and thermistors. A computer package is included to save measured parameters in addition to data organization and analysis. 
The main goal of current work is to perform regular recording of UVB and global solar radiation and ambient temperature from $1^{\text {st }}$ January 2014 till end of December 2019. The measurements are recorded then saved each ten minutes. Hourly global, UVB radiation and ambient temperature have been measured since $1^{\text {st }}$ January 2014 till $31^{\text {st }}$ December 2019. Clear sky data only are considered for analysis while cloudy days data are neglected. To ensure the accuracy of the measured parameters, a regular calibration was performed following constructions advised by Biometer manufacturer. The pyranometer used for global radiation monitoring are tested utilizing first class Eppley PSP pyranometer.

\section{Error Analysis}

UVB radiation measurement accuracy is found to be about $\pm 1.9 \%$ for the total day. An extensive statistical analysis is performed to ensure the reliability of determined mean daily records. This was achieved through calculating correlation coefficient and then adapting these data to evaluate the standard errors of both the monthly average daily values and the monthly average daily standard deviations. Standard errors calculated are smaller than the internal measurements of the devices employed. Global radiation records have measurement error of about $1.8 \%-3.3 \%$, whereas UVB radiation errors are about $1.91 \%$. The error of ambient air temperature is about $1.2 \%$.

\section{Results and Discussions}

The average UVB and global radiation monitored monthly through each hour of the day are determined. The highest hourly average UVB radiations are achieved during May-September at midday. Also, lowest UVB values take place during November, December, and January. The same trend is noticed for the values of average monthly total radiation. The maximum average hourly global radiation is achieved during May to September at midday with greatest value of 944.28 $\mathrm{W} / \mathrm{m}^{2}$ for average hourly global radiation. The smallest total radiation happens during November, December and January which are lowest UVB radiation months. The smallest global radiation measured is $437.6 \mathrm{~W} / \mathrm{m}^{2}$ at $12: 00$ noon in January. These predictions obviously indicate the powerful correlation linking UVB and global radiation.

Diurnal UVB radiation variation versus time have the same style for clear sky hours. As an illustration, Figure 1 presents the change of UVB radiation against with time for the specific day of peak collected daily UVB radiation for each year all over the studied period. As Figure 1 indicates, UVB radiation rises when solar elevation increases and achieves the peak during 12:00 to 13:00 noon, then it reduces when sun elevation reduces. The maximum UVB attained is 3.382 MED for the day of $17^{\text {th }}$ May 2015 at 12:00 noon and the maximum daily accumulated UVB radiation is 21.137 MED for $18^{\text {th }}$ June 2014. On the other hand, Figure 2 presents diurnal UVB radiation variation along time for the day of minimum collected daily UVB radiation for each year all over the studied period. The same behavior is observed again and the minimum daily accumulated UVB radiation 
is 5.206 MED and occurs at $3^{\text {rd }}$ January 2018. The maximum UVB radiation obtained, 21.137 MED, is approximately four times greater than the one obtained at the day of the least collected daily UVB (5.206 MED). This great deviation is primarily because of the existence of tiny sand particles, which will cause a reduction in UVB radiation minimum values. Also, this may be attributed to clear atmosphere, which will lead to a rise maximum UVB values. Furthermore, measurements reveal that the average data are not halfway between the minimum and the maximum but are nearer to the peak. The sharp change is basically attributed to the occasional rainfall periods, which remains less hours where the high discrepancy between the maximum and the minimum is due to less rainfall periods in Kuwait.

UVB Max (2014-2019)

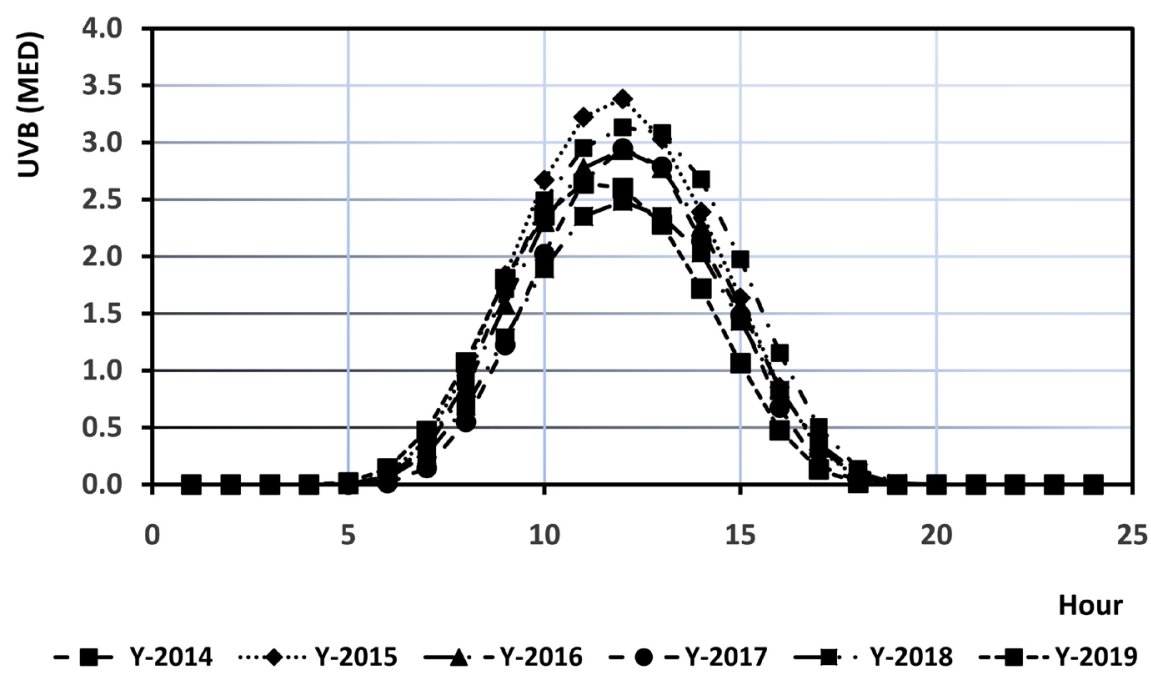

Figure 1. Diurnal variation of maximum UVB radiation for 6-years.

UVB Min (2014-2019)

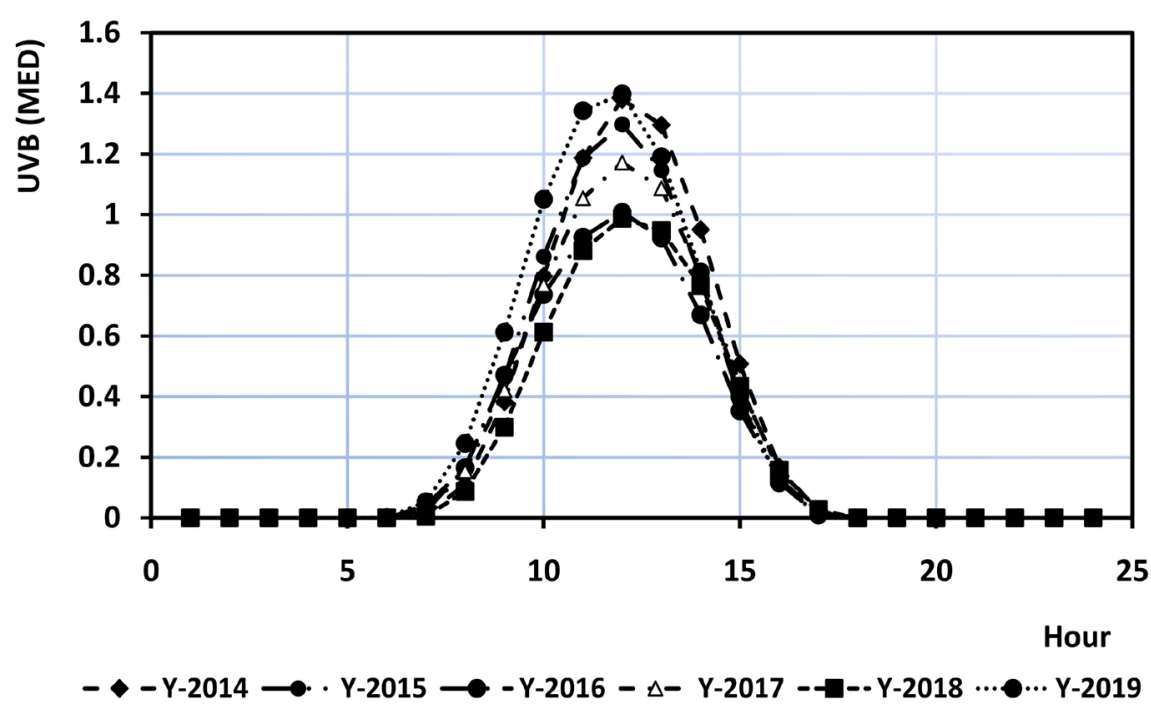

Figure 2. Diurnal variation of minimum UVB for 6-years. 


\subsection{Statistical Analysis}

The universal well-known statistical factors, root mean square error (RMSE) and mean bias error (MBE) are adapted to investigate the reliability and accuracy of various correlations utilized in this work. Positive MBE values imply that the estimated predictions overestimate the monitored data; while, MBE with negative value reveals that that the evaluated data underestimate the measured one. RMSE indicates the deviations among measured data and the corresponding one from correlations. Accurate results should have small RMSE. MBE and RMSE percentage are determined to compare between measured and predicted values. The above-mentioned statistical parameters are expressed as:

$$
\begin{gathered}
\text { RMSE }=\sqrt{\sum_{i=1}^{n}\left(X_{i}-X_{i}^{\prime}\right)^{2} / n} \\
\text { MBE }=\sum_{i=1}^{n}\left(X_{i}-X_{i}^{\prime}\right) / n \\
\text { RMSE } \%=\frac{\text { RMSE }}{\bar{X}} \times 100 \\
\text { MBE } \%=\frac{\text { MBE }}{\bar{X}} \times 100
\end{gathered}
$$

where, $X_{i}$ is the $i^{\text {th }}$ calculated value, $X_{i}^{\prime}$ is the $i^{\text {th }}$ measured value, $n$ is the data points number and $\bar{X}$ is the measured mean.

In addition, RMSE percent is the variation coefficient (CV\%) judging changes related to the mean and is commonly employed to compare the relative dispersion in two types of data. The correlation coefficient $(R)$ is a helpful factor in measuring the reliability of the correlation linking various parameters. The correlation coefficient $(R)$ is an indicator of the reliability of the measurements fitting. The correlation coefficient $(R)$ indicates the power of linear relation between two factors. The equation for determining $R$ for two parameters:

$$
R=\frac{\sum_{i=1}^{n}\left(X_{i}-\bar{X}\right)\left(Y_{i}-\bar{Y}\right)}{\sqrt{\sum_{i=1}^{n}\left(X_{i}-\bar{X}\right)^{2} \sum_{i=1}^{n}\left(Y_{i}-\bar{Y}\right)^{2}}}
$$

The typical values of $R$ is $-1 \leq R \leq+1$, the positive and negative signs are used for negative and positive linear correlations, respectively. $R$ is very near to +1 for parameters having powerful positive linear correlation. $R$ with negative values illustrates if one variable increases, the other variable decreases. On the other hand, if one variable increase leads to an increase in the other variable, this means that $\mathrm{R}$ has a positive value. If the two parameters have a powerful negative linear correlation, $R$ is close to -1 . A perfect negative fit ocfcurs when $R$ is exactly -1 . A value close to zero implies that there is a random, nonlinear relationship between the two parameters. In case of no linear correlation, $R$ is close to 0 . An ideal correlation of \pm 1 exists if all data observations located on a straight line. If 
$R>0.9$, the correlation is accepted, while it is not accepted if $R$ is smaller than 0.5 .

Coefficient of Determination $\left(R^{2}\right)$ defined as explained variation divided by total variation is important as it shows portion of the variation in one parameter that is predicted from the other variable. The range of coefficient of determination is $0 \leq R^{2} \leq 1$, and it characterizes the strength of the linear relation between two variables. So, the coefficient of determination is an indication of the reliability of the regression analysis. Usually $R^{2}$ values greater than 0.80 is accepted, whereas if it is smaller than 0.50 it is usually not satisfactory.

\subsection{Correlation between UVB and Global Radiation}

A strong correlation is found between UVB and global radiation, especially for low to moderate global radiation. This relation allows prediction of UVB radiation in desert regions where UVB recording are not possible whereas global radiation is available. Regression analysis utilizing well-known SPSS package is employed to illustrate a correlation among global and UVB radiation. Also, regression analysis is used to predict a relation correlating UVB radiation and temperature. Resulted equation can be employed to determine UVB radiations that are not possible to measure at different Kuwait sites.

Graphical charts are also utilized as they can give detailed knowledge as well as a good way of data interpretation. However, the huge data included in a graphical chart make it not easy to measure the accuracy of the results. Regression analysis is performed utilizing daily total UVB and total radiation for study months from $1^{\text {st }}$ January 2014 to $31^{\text {st }}$ December 2019. Various correlation quadratic, linear as well as cubic one is investigated to achieve the most suitable correlation corresponding to different months using the indicators RMSE, MBE and $R^{2} . R^{2}$ must be very near to 1 to obtain precise and reliable results. Statistical procedure begins by evaluating mean daily UVB and global radiation to achieve a formula relating monitored UVB and G. That job is carried out by calculating standard error of average monthly daily of UVB and total radiation. Results showed that the standard error of daily measured data is smaller than the measurement uncertainty in measuring the UVB recorded by Biometer and pyranometer data for global radiation.

Table 1 introduces the evaluated equations relating UVB and global radiation for different months from beginning of January 2014 to the end of December 2019 along $R^{2}$. A visual test is performed for experimental data plotting. This indicated that linear formula does not give a reasonable fit instead it shows a certain quadratic correlation. The quadratic relations give larger $R^{2}$ values, however fitting the measurements to cubic equation leads to greater $R^{2}$. Therefore, cubic equation is selected to relate monitored UVB to global radiation (G). An equation is chosen for each month through comparing evaluated and recorded UVB radiation. The factors utilized to judge correlation reliability are MBE, RMSE and coefficient of variation percentage (CV\%). 
Table 1. Relations between UVB (MED) and global $\left(\mathrm{Wh} / \mathrm{m}^{2}\right)$ radiation.

\begin{tabular}{ccc}
\hline Month & Cubic Equation & $R^{2}$ \\
\hline Jan & $0.689+0.0017 \mathrm{G}-5.764 \times 10^{-08} \mathrm{G}^{2}-3.357 \times 10^{-12} \mathrm{G}^{3}$ & 0.971 \\
Feb & $2.489+0.0007 \mathrm{G}+3.124 \times 10^{-07} \mathrm{G}^{2}-2.658 \times 10^{-11} \mathrm{G}^{3}$ & 0.952 \\
Mar & $17.324-0.008 \mathrm{G}+2.429 \times 10^{-06} \mathrm{G}^{2}-2.117 \times 10^{-10} \mathrm{G}^{3}$ & 0.951 \\
Apr & $-11.905+0.0103 \mathrm{G}-1.862 \times 10^{-06} \mathrm{G}^{2}+1.132 \times 10^{-10} \mathrm{G}^{3}$ & 0.984 \\
May & $9.046-0.0013 \mathrm{G}+4.712 \times 10^{-07} \mathrm{G}^{2}-1.304 \times 10^{-11} \mathrm{G}^{3}$ & 0.965 \\
Jun & $522.308-0.315 \mathrm{G}+4.329 \times 10^{-05} \mathrm{G}^{2}-1.821 \times 10^{-9} \mathrm{G}^{3}$ & 0.971 \\
Jul & $243.453+0.1123 \mathrm{G}-1.487 \times 10^{-05} \mathrm{G}^{2}+7.321 \times 10^{-10} \mathrm{G}^{3}$ & 0.959 \\
Aug & $-249.824+0.134 \mathrm{G}-2.233 \times 10^{-05} \mathrm{G}^{2}+9.652 \times 10^{-10} \mathrm{G}^{3}$ & 0.987 \\
Sep & $26.255-0.0336 \mathrm{G}+6.328 \times 10^{-06} \mathrm{G}^{2}-5.120 \times 10^{-10} \mathrm{G}^{3}$ & 0.958 \\
Oct & $127.854-0.0832 \mathrm{G}+1.490 \times 10^{-05} \mathrm{G}^{2}-1.004 \times 10^{-9} \mathrm{G}^{3}$ & 0.961 \\
Nov & $4.865-0.003 \mathrm{G}+3.174 \times 10^{-07} \mathrm{G}^{2}+2.224 \times 10^{-11} \mathrm{G}^{3}$ & 0.955 \\
Dec & $-30.432+0.042 \mathrm{G}-1.012 \times 10^{-05} \mathrm{G}^{2}+2.234 \times 10^{-09} \mathrm{G}^{3}$ & 0.968 \\
\hline
\end{tabular}

Larger coefficient of determination $\left(R^{2}\right)$ indicates that there is a powerful correlation among UVB and G. The $R^{2}$ values is larger than 0.95 for all study period and the greatest value attained is 0.987 for August, while the lowest $R^{2}$ noticed is 0.951 for March. MBE, MBE\%, RMSE, and CV\% (RMSE\%) are presented in Table 2 for different months.

The statistical analysis of recorded data presented in Table 2 clearly shows the power relation between UVB and global radiation, especially for moderate to small global solar radiation. In addition, predicted UVB radiation from the recorded global one agrees well with the measured UVB radiation. That is illustrated by almost small statistical factors examined, MBE, RMSE and CV\%. The smallest percent CV is $5.993 \%$ at August and the largest percentage CV is $11.847 \%$ for March. Also, CV\% does not surpass $11.9 \%$ verifying that correlations estimated for UVB radiation are accurate. So, predicted formula can be adapted to determine UVB radiation precisely for regions where monitoring of UVB radiation are not possible. It should be mentioned that the relatively smaller $\mathrm{CV}$ values in Table 2 occurs through months of maximum radiation, which is primarily due to clear sky climate in these periods. The large predicted errors in certain relations may be associated with small UVB values in comparison to the correspondent global radiation. So, lower error in UVB will cause relatively higher errors in the correlations. Further, it is useful to mention that ozone has a significant effect in UVB attenuation, however its impact on global radiation can be neglected.

Figure 3 shows the relation between UVB radiation predicted from global radiation against recorded UVB data for the study period after eliminating data measured in cloud sky days. As figure indicates, the fit is a line having zero intercept and almost a unity slope (0.984). 
Table 2. Statistical errors for UVB relationships.

\begin{tabular}{ccccc}
\hline Month & MBE & MBE\% & RMSE & CV\% (RMSE\%) \\
\hline Jan & -0.0212 & -0.0188 & 0.546 & 9.331 \\
Feb & 0.0019 & 0.0032 & 0.921 & 10.229 \\
Mar & 0.0019 & 0.0425 & 2.334 & 11.847 \\
Apr & -0.0022 & -0.0172 & 1.860 & 10.521 \\
May & 0.0018 & 0.0006 & 1.463 & 7.824 \\
Jun & 0.0019 & 0.0007 & 1.547 & 8.993 \\
Jul & 0.0006 & 0.0021 & 0.863 & 7.229 \\
Aug & 0.0004 & 0.0042 & 1.459 & 5.993 \\
Sep & 0.0037 & 0.0047 & 0.845 & 7.123 \\
Oct & 0.0007 & 0.0007 & 0.732 & 9.254 \\
Nov & 0.0004 & 0.0005 & 0.802 & 11.673 \\
Dec & 0.0018 & 0.0033 & 0.497 & 10.251 \\
\hline
\end{tabular}

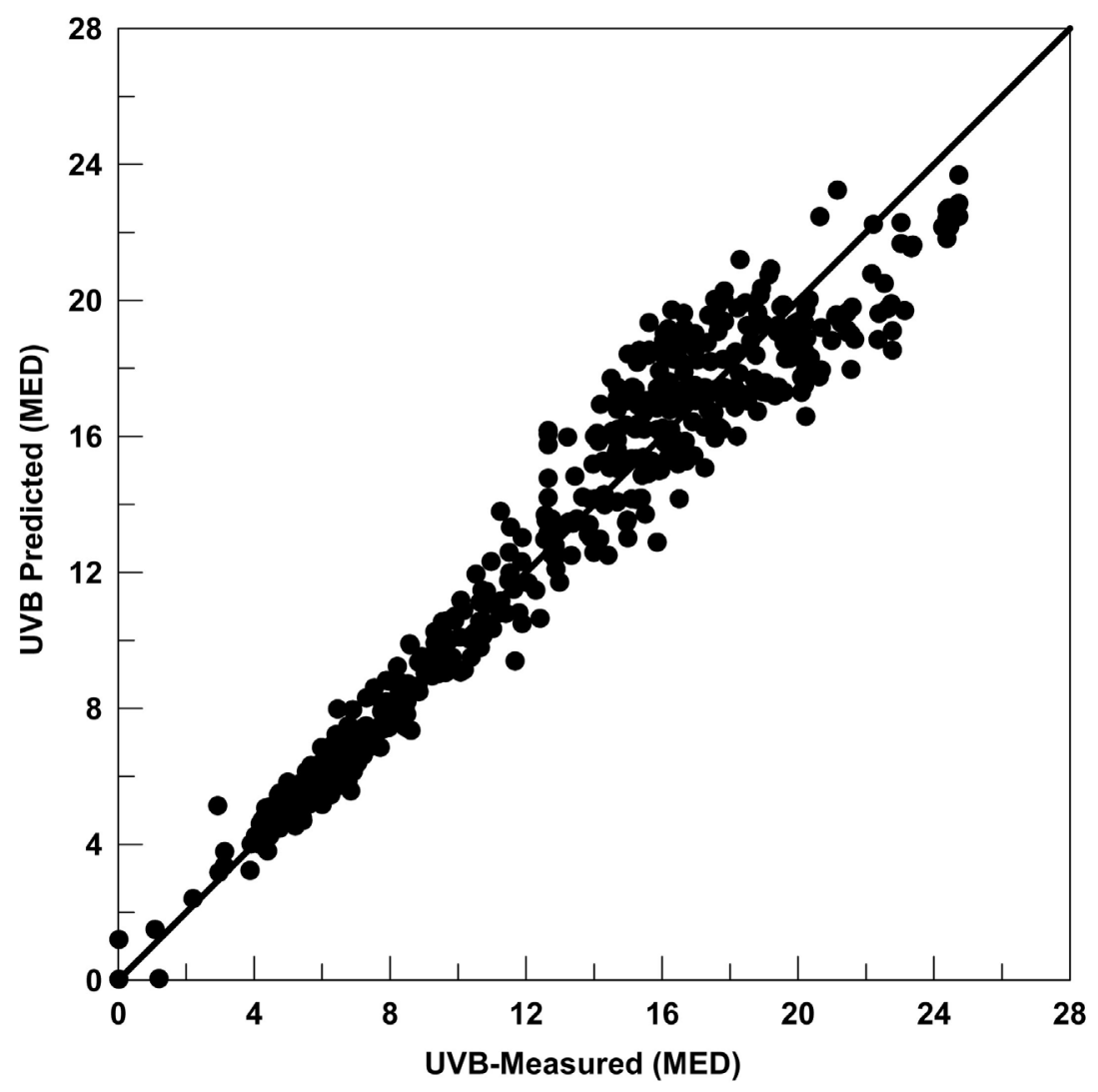

Figure 3. Calculated versus measured UVB radiation.

Furthermore, the CV percent is $10.827 \%$, which is relatively small. Current predictions let us state that the empirical formula can be utilized to accurately determine UVB radiation in any other regions in Kuwait where UVB radiation measurements are not available. 


\subsection{Relationship between UVB and Ambient Temperature}

A powerful relationship between UVB radiation and ambient temperature is predicted from the statistical analysis. A satisfactory linear correlation between the UVB and ambient temperature is predicted permitting calculation of UVB radiation in desert locations where measurements of ambient temperature are available while is no facility to measure UVB. Generally, the reliability of the utilized correlations is examined through calibration versus measured data. Regression analyses are performed employing daily ambient temperature and UVB measurements for all months of the studied period from $1^{\text {st }}$ January 2014 to $31^{\text {st }}$ December 2019. Various correlations linear, quadratic and cubic relations are investigated to predict the most suitable correlation considering the values of RMSE, MBE and $R^{2}$. The initial procedure in error investigation is to decide if the values of monthly average daily UVB and ambient temperature represent the site or not. This is a crucial point to find a correlation between recorded UVB and ambient temperature. This job is achieved by evaluating monthly average daily errors in both UVB and ambient temperature. This error is found to be smaller than the uncertainty in measurements by both Biometer and temperature measurements sensors.

The attained relations linking UVB and ambient temperature are introduced in Table 3 along $R^{2}$. Graphs of measured data obviously indicated that good fit is not a linear one, rather it is better to utilize a quadratic correlation. The quadratic empirical correlations have a significant higher $R^{2}$, however employing cubic equation gives a higher $R^{2}$. So, it is decided to select cubic equation to present the correlation between measured UVB and ambient temperature. A correlation is chosen for each month, by comparing calculated and measured UVB radiation values. RMSE, $\mathrm{MBE}$ and $\mathrm{CV} \%$ are used to measure the correlation accuracy.

The higher values of $R^{2}$, reveals that there is a powerful correlation between UVB and ambient temperature. $R^{2}$ values are larger than 0.94 and the largest value attained is 0.974 for July. Further, the smallest $R^{2}$ data obtained is 0.943 in April. Table 4 introduces MBE, MBE\%, RMSE, and CV\% (RMSE\%) results for months examined.

Table 4 shows a solid correlation between UVB radiation and ambient temperature, especially at modest to small global radiation. The predicted hourly UVB radiation from ambient temperature measurements agree well with recorded ones of UVB radiation. This is validated by relatively small MBE, RMSE and CV\%. The smallest percent $\mathrm{CV}$ is $6.179 \%$ for October whereas the greatest $\mathrm{CV}$ percentage is $12.244 \%$ for May. As Table 4 shows, CV\% does not surpass $11.8 \%$ indicating that correlations obtained for UVB radiation are accurate. So, these relations can be adapted to find UVB radiation precisely for locations with no facility to record UVB radiation. The small CV values in Table 4 are through months of maximum radiation due to clear sky weather in these periods. The relatively large errors in certain formula may be because of lower UVB in comparison to global radiation. So, small absolute error in UVB radiation will lead to a higher error in predicted formula. In addition, it is substantial to mention that ozone has significant effect in UVB attenuation, but its impact on global radiation can be ignored. 
Table 3. Correlations between UVB (MED) and ambient temperature, $\mathrm{T}_{\mathrm{a}}\left({ }^{\circ} \mathrm{C}\right)$.

\begin{tabular}{ccccc}
\hline Month & \multicolumn{2}{c}{ Cubic Equation } & $R^{2}$ \\
\hline Jan & $0.534+0.0021 \mathrm{~T}_{\mathrm{a}}-7.924 \times 10^{-08}$ & $\mathrm{~T}_{\mathrm{a}}^{2}-4.226 \times 10^{-10}$ & $\mathrm{~T}_{\mathrm{a}}^{3}$ & 0.966 \\
Feb & $3.436+0.0008 \mathrm{~T}_{\mathrm{a}}+2.983 \times 10^{-06}$ & $\mathrm{~T}_{\mathrm{a}}^{2}-3.765 \times 10^{-12}$ & $\mathrm{~T}_{\mathrm{a}}^{3}$ & 0.958 \\
Mar & $22.138-0.005 \mathrm{~T}_{\mathrm{a}}+3.256 \times 10^{-07}$ & $\mathrm{~T}_{\mathrm{a}}^{2}-5.234 \times 10^{-11}$ & $\mathrm{~T}_{\mathrm{a}}^{3}$ & 0.953 \\
Apr & $10.705+0.02063 \mathrm{~T}_{\mathrm{a}}-4.912 \times 10^{-07}$ & $\mathrm{~T}_{\mathrm{a}}^{2}+2.082 \times 10^{-11}$ & $\mathrm{~T}_{\mathrm{a}}^{3}$ & 0.943 \\
May & $7.259-0.0025 \mathrm{~T}_{\mathrm{a}}+6.123 \times 10^{-06}$ & $\mathrm{~T}_{\mathrm{a}}^{2}-3.882 \times 10^{-11}$ & $\mathrm{~T}_{\mathrm{a}}^{3}$ & 0.967 \\
Jun & $8.224-0.654 \mathrm{~T}_{\mathrm{a}}+5.231 \times 10^{-06}$ & $\mathrm{~T}_{\mathrm{a}}^{2}-4.721 \times 10^{-8}$ & $\mathrm{~T}_{\mathrm{a}}^{3}$ & 0.958 \\
Jul & $221.213+0.138 \mathrm{~T}_{\mathrm{a}}-3.524 \times 10^{-05}$ & $\mathrm{~T}_{\mathrm{a}}^{2}+3.921 \times 10^{-11}$ & $\mathrm{~T}_{\mathrm{a}}^{3}$ & 0.974 \\
Aug & $215.532+0.179 \mathrm{~T}_{\mathrm{a}}-3.339 \times 10^{-07}$ & $\mathrm{~T}_{\mathrm{a}}^{2}+6.981 \times 10^{-9}$ & $\mathrm{~T}_{\mathrm{a}}^{3}$ & 0.964 \\
Sep & $37.125-0.0416 \mathrm{~T}_{\mathrm{a}}+8.328 \times 10^{-05}$ & $\mathrm{~T}_{\mathrm{a}}^{2}-8.146 \times 10^{-11}$ & $\mathrm{~T}_{\mathrm{a}}^{3}$ & 0.958 \\
Oct & $152.773-0.0654 \mathrm{~T}_{\mathrm{a}}+4.765 \times 10^{-05}$ & $\mathrm{~T}_{\mathrm{a}}^{2}-3.176 \times 10^{-10}$ & $\mathrm{~T}_{\mathrm{a}}^{3}$ & 0.963 \\
Nov & $6.159-0.004 \mathrm{~T}_{\mathrm{a}}+7.129 \times 10^{-06}$ & $\mathrm{~T}_{\mathrm{a}}^{2}+8.317 \times 10^{-11}$ & $\mathrm{~T}_{\mathrm{a}}^{3}$ & 0.957 \\
Dec & $4.578+0.148 \mathrm{~T}_{\mathrm{a}}-6.579 \times 10^{-06}$ & $\mathrm{~T}_{\mathrm{a}}^{2}+6.152 \times 10^{-10}$ & $\mathrm{~T}_{\mathrm{a}}^{3}$ & 0.968 \\
\hline
\end{tabular}

Table 4. Statistical errors for UVB correlations.

\begin{tabular}{ccccc}
\hline Month & MBE & MBE\% & RMSE & CV\% (RMSE\%) \\
\hline Jan & -0.0336 & -0.0133 & 0.613 & 8.441 \\
Feb & 0.0022 & 0.0029 & 0.887 & 7.339 \\
Mar & 0.0033 & 0.0521 & 3.561 & 10.747 \\
Apr & -0.0042 & -0.0161 & 2.734 & 11.712 \\
May & 0.0028 & 0.0007 & 3.548 & 12.244 \\
Jun & 0.0027 & 0.0008 & 3.661 & 8.623 \\
Jul & 0.0007 & 0.0019 & 0.992 & 6.238 \\
Aug & 0.0005 & 0.0051 & 2.134 & 7.225 \\
Sep & 0.0052 & 0.0036 & 0.784 & 7.892 \\
Oct & 0.0008 & 0.0008 & 0.748 & 6.179 \\
Nov & 0.0005 & 0.0004 & 0.923 & 11.123 \\
Dec & 0.0021 & 0.0029 & 0.551 & 10.742 \\
\hline
\end{tabular}

To further validate the correlation among measured UVB radiation and ambient temperature, Figures 4(a)-(f) presents the variation of both UVB radiation and ambient temperature all over the year for the different years measured.

As seen from Figure 4. UVB radiation and ambient temperature follow the same trend for all years. As seen, both UVB radiation and ambient temperature increases in the first half of the year then decreases for all the years studied. However, it is noted that the rate of UVB decrease is slower than the rate of temperature decreases for the second half of the year. It is stated that in the Arabian Peninsula, which is a desert region, dust behavior is usually maximum from May to Jun during spring and summer seasons since dust storms are more expected at these times. The dust storms behavior leads to the existence of dust aerosols in Kuwait atmosphere which decreases the global radiation as well as UVB radiation and the air temperature due to scattering and dust absorption [38] [39]. 


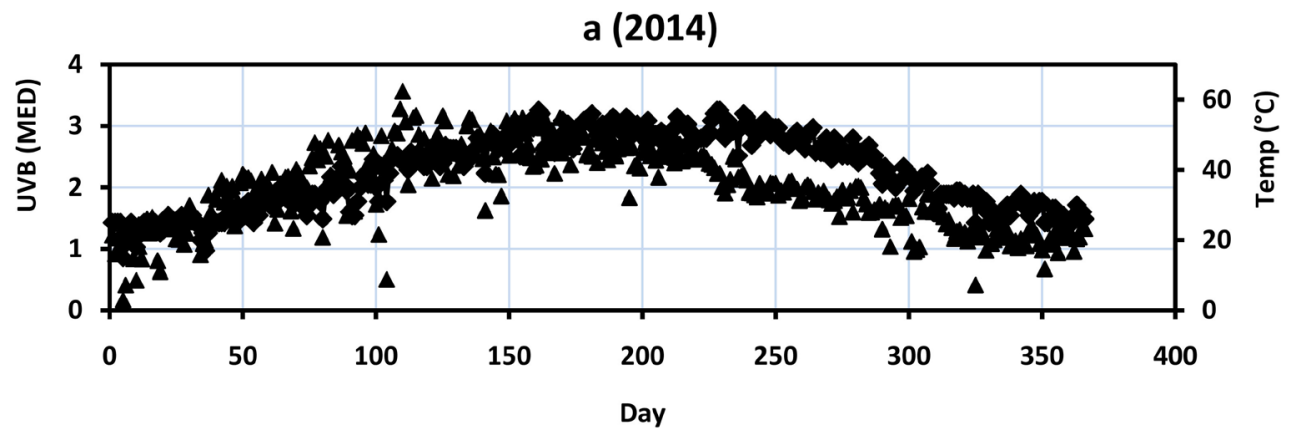

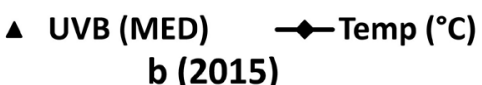

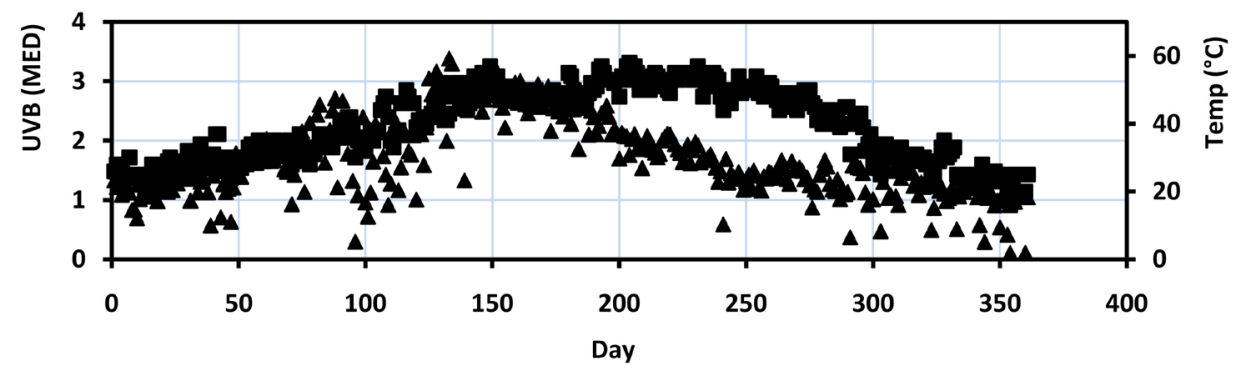

$\triangle$ UVB (MED) - Temp ( $\left.{ }^{\circ} \mathrm{C}\right)$

c (2016)
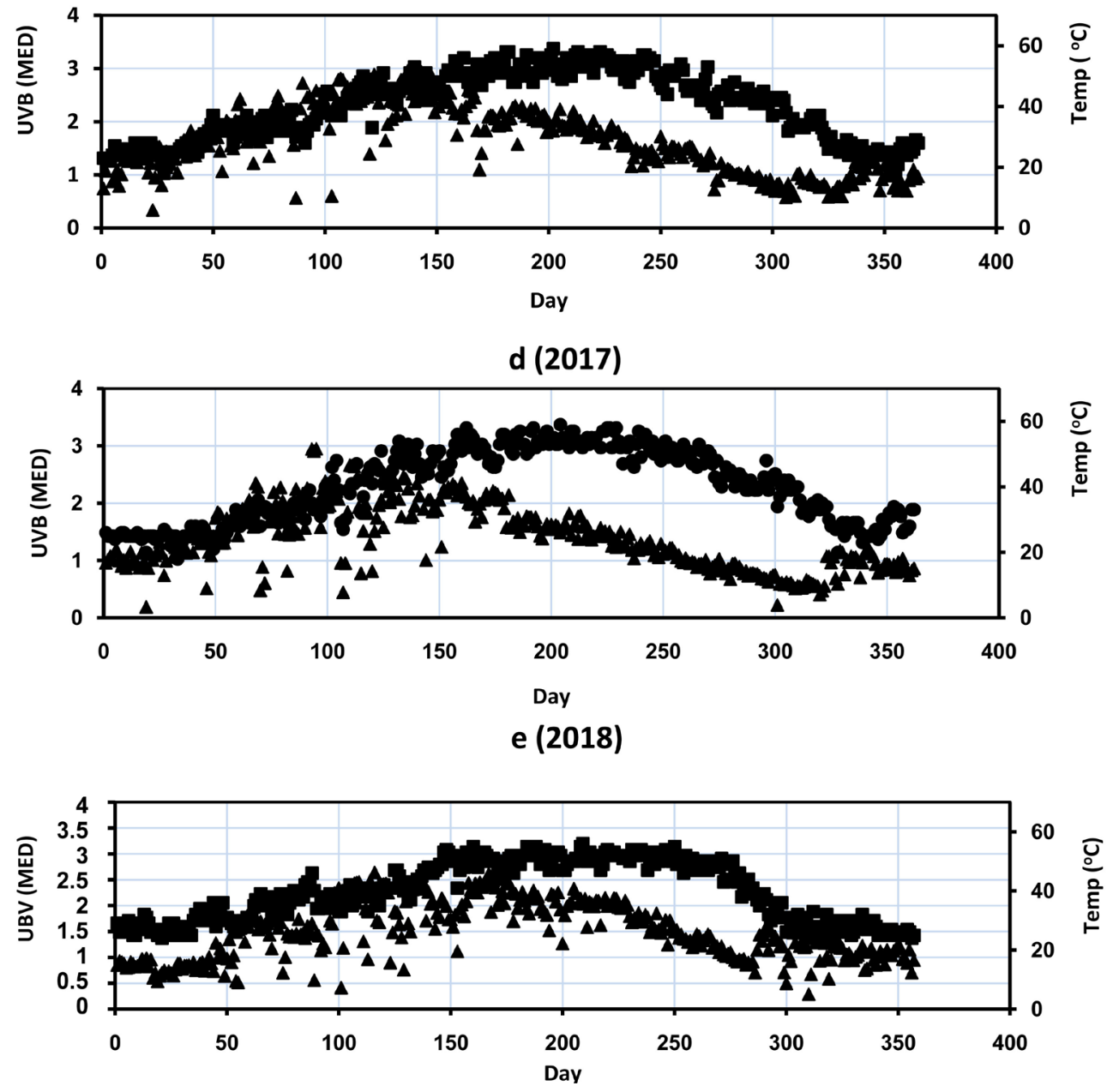
f (2019)

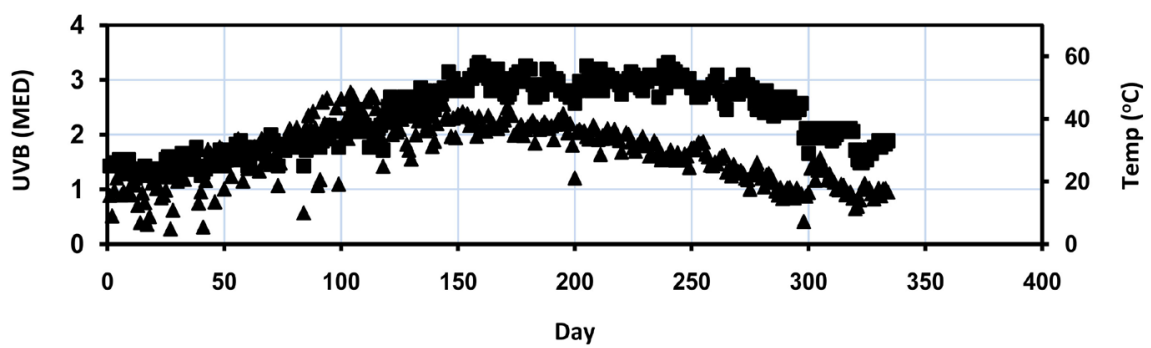

Figure 4. Variation of UVB and temperature for the studied years.

However, as illustrated in this Figure 4, the fast rate decrease of UVB values (short wavelength) in the second half year in all the studied period may be attributed to dust aerosols in Kuwait. So, the ambient temperature decreases at slowly rate compared to UVB decrease rate. This behavior may be attributed to other climate parameters changes as high summer IR infrared radiation (IR), radiative dust aerosols, air pollution, etc. from one year to another.

To further validate the relation among UVB radiation and ambient temperature another analysis is carried out. Since ambient temperature greatly varies all over the year in Kuwait from about $20^{\circ} \mathrm{C}$ to about $60^{\circ} \mathrm{C}$, so this can enable studying the variation of UVB with ambient temperature in a different manner. The average maximum daily UVB value corresponding to a specific temperature all over the year for the studied period is evaluated. Figures 5(a)-(f) shows the relation between the ambient temperature and the corresponding average maximum daily UVB radiation. As seen the relation is a linear one for all the period studied and the coefficient of determination $\left(R^{2}\right)$ for all years is nearly 0.9 which means that it is in the range of the accepted values considering the changes in global climate conditions.

Figure 6 summarizes the above-mentioned procedure for the years studied. This figure illustrates clearly that the relation between UVB and ambient temperature is a linear one.

\subsection{UV Index}

Exposure to low amounts of UV radiation is useful and produce vitamin D. Though, extra amounts of UV radiation cause two essential health dilemma: cataract and skin cancer. Solar UV index (UVI) defines UV radiation levels at the surface of the Earth. So, information regarding UVI values is necessary for adverse health effects and at the same time increase public awareness so that they can protect themselves from long exposure to UV radiation. Higher UVI values indicate the great potential for skin and eye and consequently small time is needed to cause harmful effects. UV radiation levels change through the day and achieves its peak value at 12:00 noon. So, UVI usually determines the maximum UV radiation supposed to be received by Earth at midday. UVI values can reach up to 20 for regions near the equator. The exposure divisions related to different UVI 
values UVI [31] are: small $<4,4 \leq$ modest $\leq 7,7<$ high $\leq 9$ and extreme $\geq 9$. The effective power of $1 \mathrm{MED} / \mathrm{h}$ is equivalent to $0.0583 \mathrm{Wm}^{-2}$, therefore UVB radiation in $\mathrm{MED} / \mathrm{h}$ should be initially transferred to $\mathrm{W} / \mathrm{m}^{2}$ and multiplied by 40 to evaluate the value of UVI. Table 5 introduces UVI results for various months during the hours of midday (10 - 14) which is the range correspond to the highest UVI evaluated. Also, CV\% is evaluated and introduced along UVI data. To specify risky periods to sun exposure, the UVI values larger than 6 are introduced in boldface character.

a (2014)
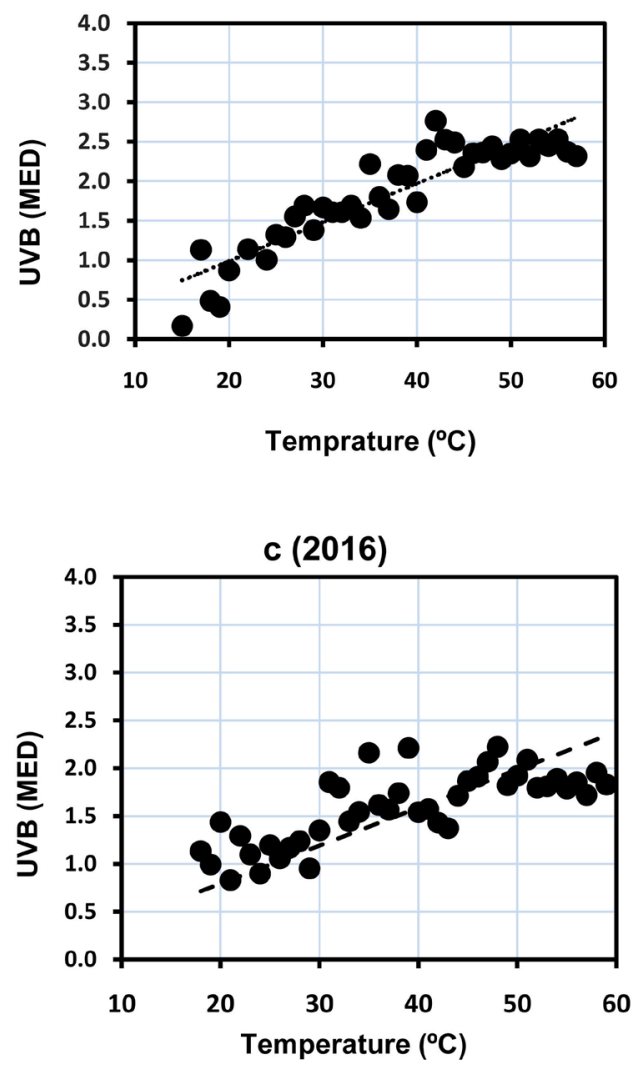

e (2018)

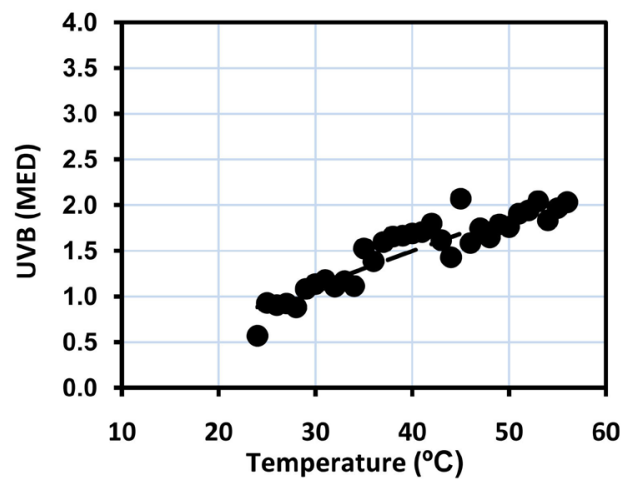

b (2015)

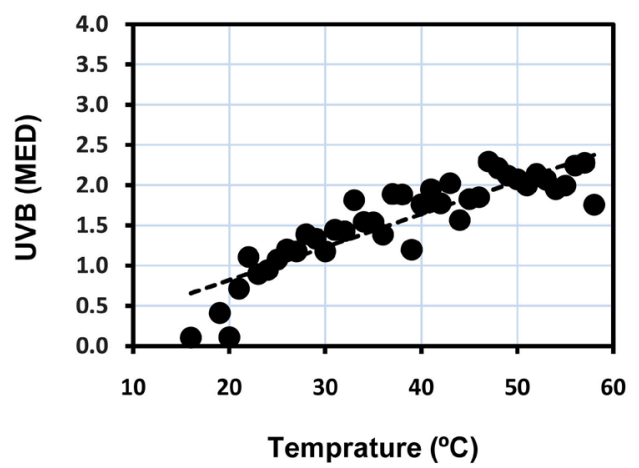

d (2017)

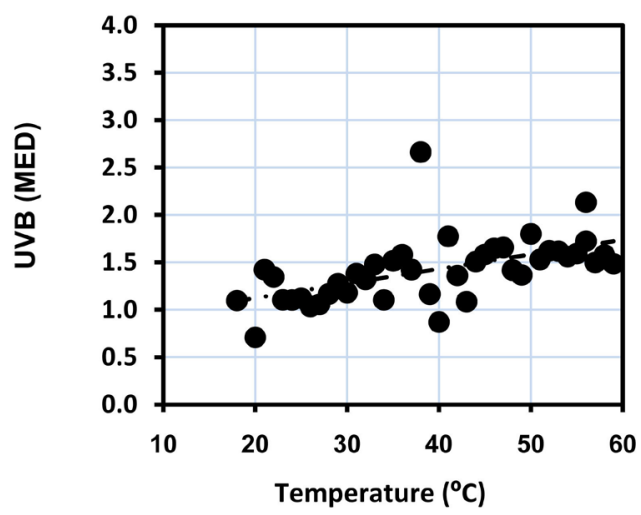

f (2019)

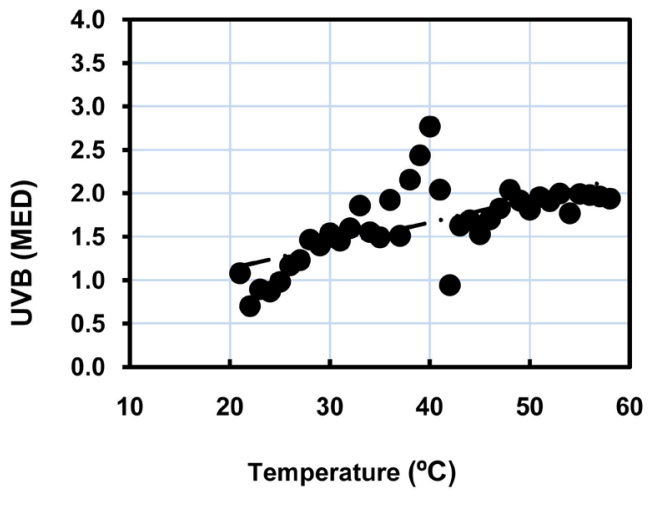

Figure 5. Variation of average UVB with specific ambient temperature for the years studied. 


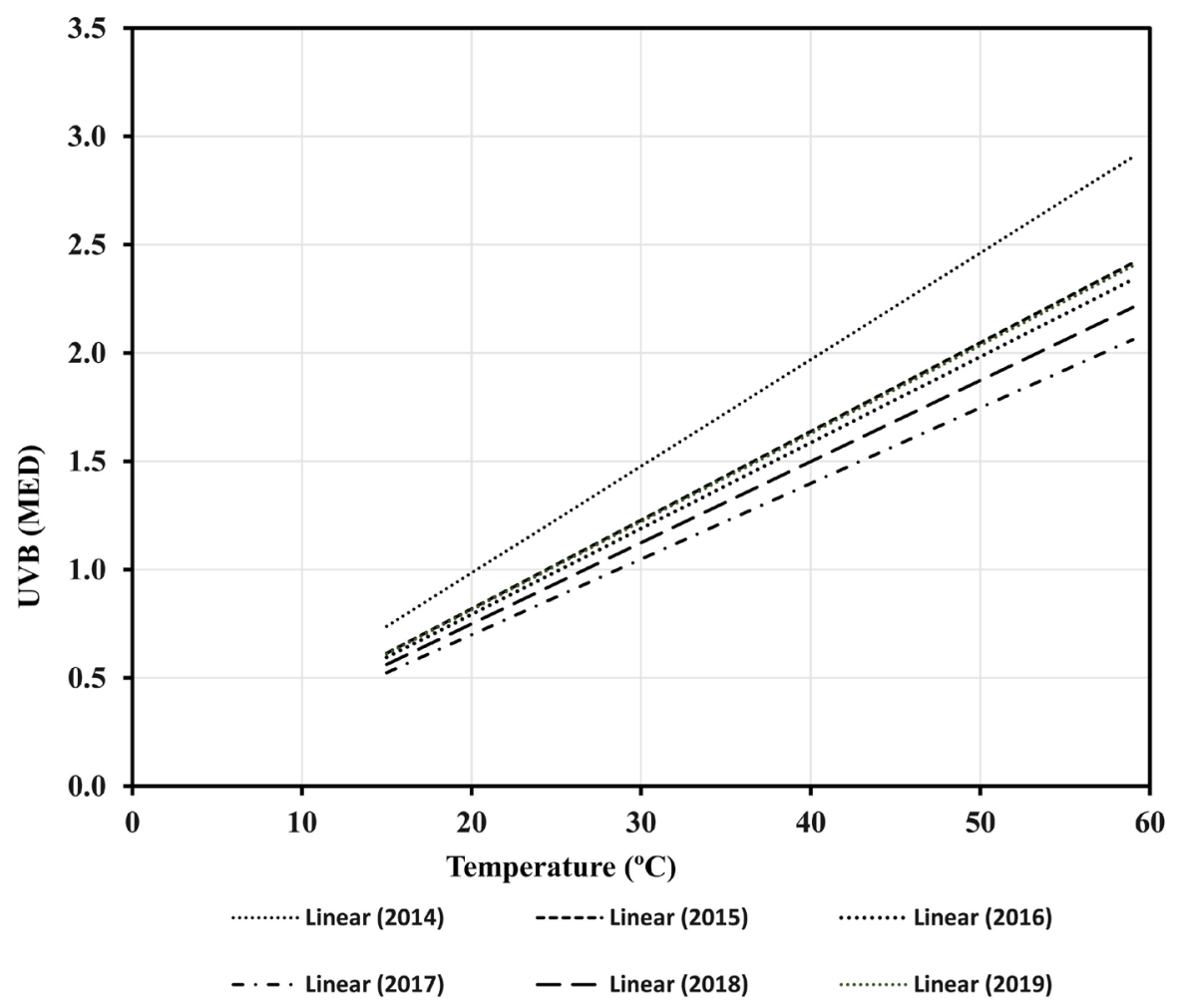

Figure 6. Linear relation between UVB and ambient temperature for the years studied.

Table 5. Average hourly UVI at midday.

\begin{tabular}{ccccc}
\hline Month & $10-11$ & $11-12$ & $12-13$ & $13-14$ \\
\hline Jan & $2.41(10 \%)$ & $4.14(7 \%)$ & $2.79(11 \%)$ & $2.54(11 \%)$ \\
Feb & $2.54(8 \%)$ & $3.69(11 \%)$ & $5.28(10 \%)$ & $4.12(14 \%)$ \\
Mar & $5.21(12 \%)$ & $5.44(12 \%)$ & $6.14(12 \%)$ & $3.88(11 \%)$ \\
Apr & $4.64(10 \%)$ & $6.28(11 \%)$ & $4.88(8 \%)$ & $3.93(11 \%)$ \\
May & $5.76(10 \%)$ & $6.73(10 \%)$ & $6.51(12 \%)$ & $5.44(10 \%)$ \\
Jun & $6.54(11 \%)$ & $6.91(12 \%)$ & $6.53(9 \%)$ & $5.68(11 \%)$ \\
Jul & $5.38(12 \%)$ & $6.83(13 \%)$ & $6.34(12 \%)$ & $5.14(12 \%)$ \\
Aug & $6.15(10 \%)$ & $7.62(11 \%)$ & $6.89(11 \%)$ & $6.12(10 \%)$ \\
Sep & $5.112(11 \%)$ & $5.45(12 \%)$ & $5.63(11 \%)$ & $5.26(8 \%)$ \\
Oct & $2.77(12 \%)$ & $4.87(11 \%)$ & $3.82(10 \%)$ & $2.88(10 \%)$ \\
Nov & $3.84(12 \%)$ & $3.53(11 \%)$ & $2.14(12 \%)$ & $2.42(10 \%)$ \\
Dec & $2.58(12 \%)$ & $2.12(12 \%)$ & $2.33(11 \%)$ & $1.63(12 \%)$ \\
\hline
\end{tabular}

Figures 7-10 illustrates monthly mean hourly UVI change during the day for all months the study period. As figures illustrate, the UVI on the y-axis have been split to three major levels awing to commonly known categories of UVI: small $<$ $4,4 \leq$ moderate $\leq 7$ and $7 \leq$ high $\leq 9$. As indicated, evaluated UVI data is not over the risky value $(\geq 9)$. Various levels can be interpreted due to exposure to sun to attain redness of a type 2 skin. The mentioned levels of UVI corresponds to $<15,20,30 \mathrm{~min}$ and more than $1 \mathrm{~h}$, respectively. As shown from Table 5 and 
Figures 7-10, UVI do not exceed the dangerous value $(\geq 9)$ in any time of the day all over the year. The greatest UVI are obtained during May-August at midday hours. In addition, it is noted that the values of UVI from 12 - 14 are usually smaller than from 10 - 12. This trend because of the difference between solar time and standard local time during the year. Furthermore, predictions indicate that months of summer are specified by relatively small coefficient of change because of high climate durability in Kuwait weather at this time. So, relatively large coefficient of variation is caused by weather fluctuations at these months.

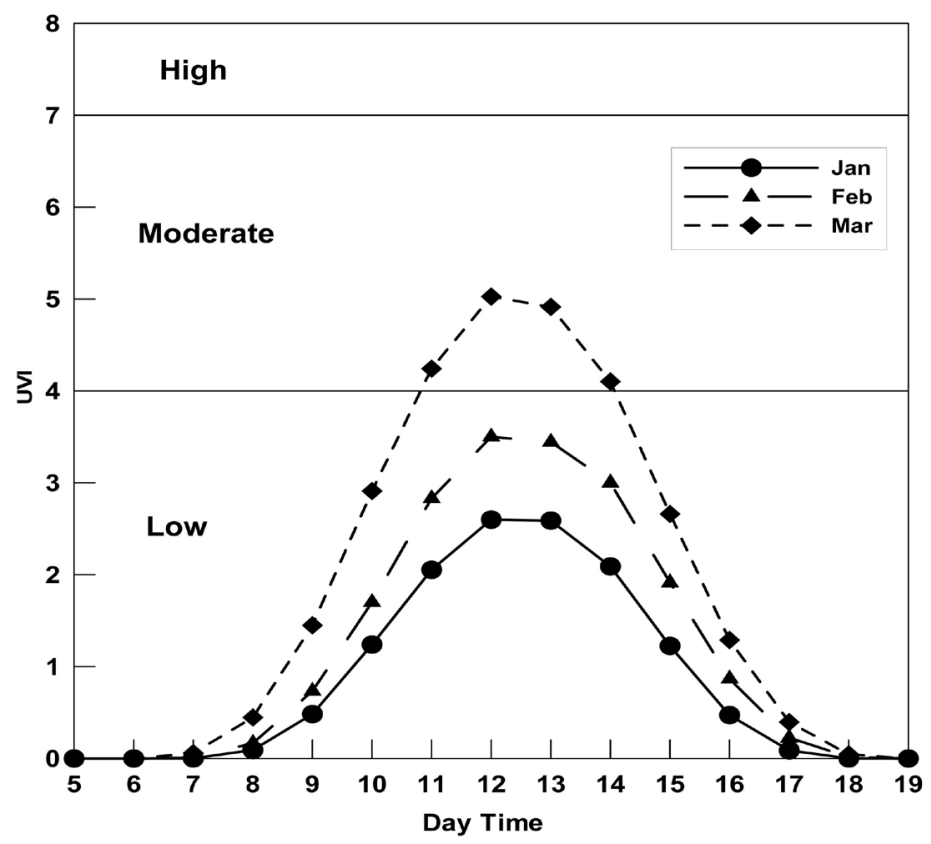

Figure 7. Average hourly UVI for January-March).

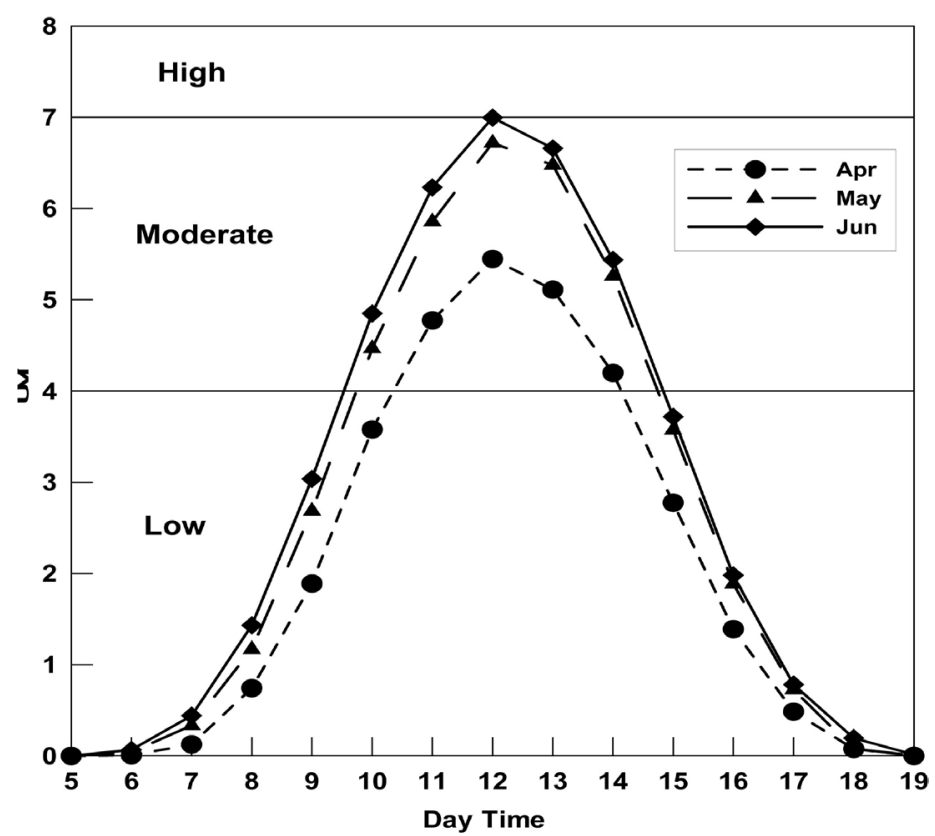

Figure 8. Average hourly UVI for April-June. 


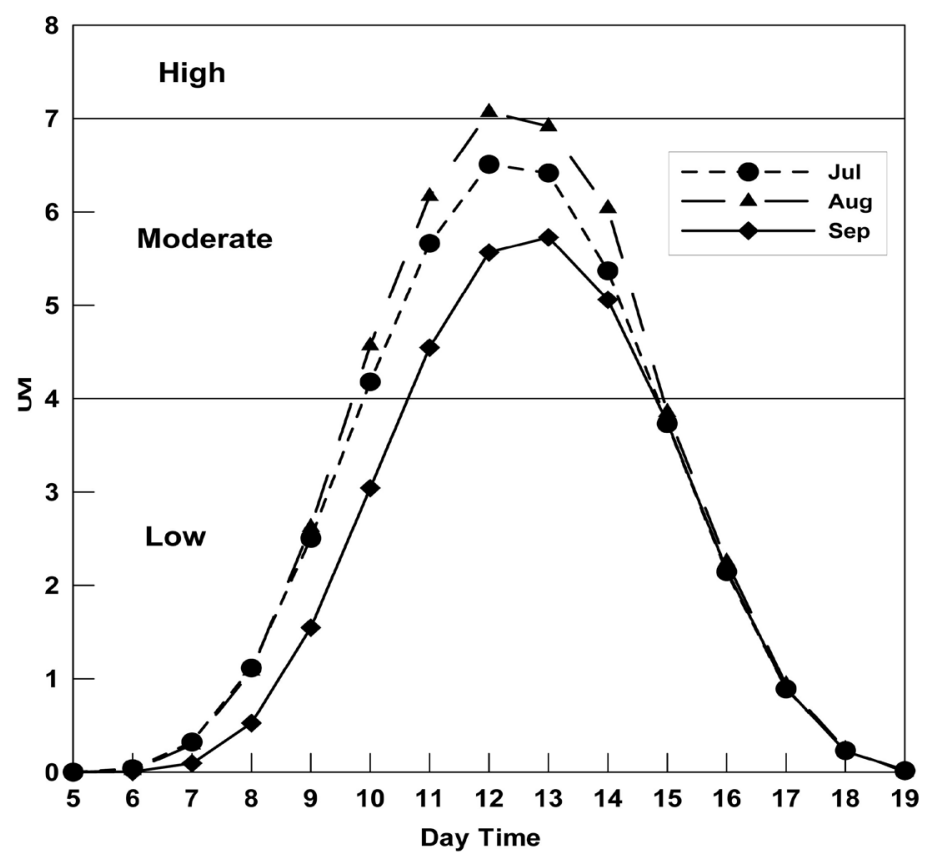

Figure 9. Average hourly UVI for July-September.

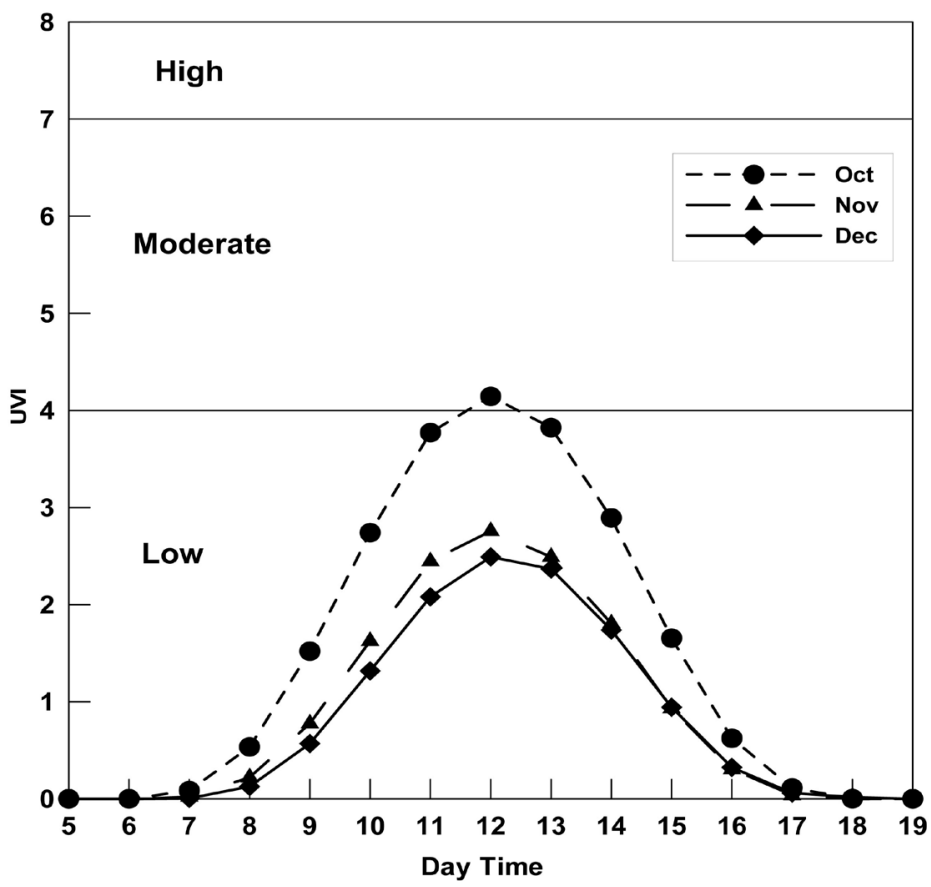

Figure 10. Average hourly UVI for October-December.

\section{Conclusions}

UVB) radiation, ambient temperature and global solar radiation are recorded at Shuwaikh, Kuwait from January $1^{\text {st }}, 2014$ until December $31^{\text {st }}, 2019$. Following conclusions can be stated based on current work results:

- A strong correlation exists among UVB, global radiation and ambient temperature specifically in the range of modest to small global radiation levels. 
- UVB radiation peak data take place in summer months (June-August) and the maximum daily accumulated UVB radiation is 21.137 MED for $18^{\text {th }}$ June 2014.

- The lowest UVB radiation takes place in winter months (December-February) and the least daily accumulated UVB radiation is 5.206 MED and happens at $3^{\text {rd }}$ January 2018.

- The peak of UVB radiation (21.137 MED) is almost four times larger than the maximum achieved for the day of the least collected daily UVB radiation (5.206 MED).

- The large difference between maximum and minimum UVB radiation is basically because of the existence of sand particles. This will cause a reduction in minimum UVB data. In addition to the presence of clear atmosphere, which will lead to a rise in peak values of the UVB radiation.

- A significant variation of the daily UVB and global radiation all over the year is attained since it is altered by dust and cloud variations during the year.

- Diurnal global and UVB radiation change have similar behavior for all clear day's data. Typically, UVB and global radiation rise when solar elevation increases and achieves the peak during 11:00 to 13:00, then when sun elevation reduces it decreases. Furthermore, global and UVB radiation measurements are maximum approximately in midday with modest diurnal similarity.

- Cubic formula gives the most accurate correlation between UVB and G and between UVB and ambient temperature since it produces the largest $\mathrm{R}^{2}$ and the smallest $\mathrm{CV} \%$ values.

- UVI is evaluated and risky sun exposure times during the day when UVI is larger than 6 are stated for different months.

- The values of largest UVI data take place during May-August at midday hours.

- UVI values never surpass the dangerous value $(\geq 9)$ at any hour throughout all the study period.

\section{Acknowledgements}

The authors would like to thank The Public Authority for Applied Education and Training (PAAET), Kuwait for supporting this research under the project No. (TS-09-12).

\section{Conflicts of Interest}

The authors declare no conflicts of interest regarding the publication of this paper.

\section{References}

[1] Moehrle, M. (2008) Outdoor Sports and Skin Cancer. Clinics in Dermatology, 26, 12-15. https://doi.org/10.1016/j.clindermatol.2007.10.001

[2] Autier, P. (2009) Sunscreen Abuse for Intentional Sun Exposure. British Journal of Dermatology, 161, 40-45. https://doi.org/10.1111/j.1365-2133.2009.09448.x 
[3] Halliday, G.M. (2010) Common Links among the Pathways Leading to UV-Induced Immunosuppression. Journal of Investigative Dermatology, 130, 1209-1212. https://doi.org/10.1038/jid.2009.374

[4] Hart, P.H., Gorman, S. and Finlay-Jones, J. (2011) Modulation of the Immune System by UV Radiation: More than Just the Effects of Vitamin D? Nature Reviews Immunology, 11, 584-596. https://doi.org/10.1038/nri3045

[5] Reeve, V.E., Allanson, M., Domanski, D. and Painter, N. (2012) Gender Differences in UV-Induced Inflammation and immunosuppression in Mice Reveal Male Unresponsiveness to UVA Radiation. Photochemical \& Photobiological Sciences, 11, 173-179. https://doi.org/10.1039/C1PP05224A

[6] Labed, S. and Lorenzo, E. (2004) The Impact of Solar Radiation Variability and Data Discrepancies on the Design of PV Systems. Renewable Energy, 29, 1007-1022. https://doi.org/10.1016/j.renene.2003.12.009

[7] De Miguel, A. and Bilbao, J. (2005) Test Reference Year Generation from Meteorological and Simulated Solar Radiation Data. Solar Energy, 78, 695-703. https://doi.org/10.1016/j.solener.2004.09.015

[8] Korachagaon, I. and Bapat, V.N. (2012) General Formula for the Estimation of Global Solar Radiation on Earth's Surface around the Globe. Renewable Energy, 41, 394-400. https://doi.org/10.1016/j.renene.2011.11.002

[9] Kudish, A.I., Lyubansky, V., Evseev, E.G. and Ianetz, A. (2005) Inter-Comparison of the Solar UVB, UVA and Global Radiation Clearness and UV Indices for Beer Sheva and Neve Zohar (Dead Sea), Israel. Energy, 30, 1623-1641.

https://doi.org/10.1016/j.energy.2004.04.033

[10] Bilbao, J., Miguel, A., Franco, J.A. and Ayuso, A. (2004) Test Reference Year Generation and Evaluation Methods in the Continental Mediterranean Area. Journal of Applied Meteorology and Climatology, 43, 390-400. https://doi.org/10.1175/1520-0450(2004)043<0390:TRYGAE >2.0.CO;2

[11] Bilbao, J. and Miguel, A. (2013) Contribution to the Study of UV-B Solar Radiation in Central Spain. Renewable Energy, 53, 79-85. https://doi.org/10.1016/j.renene.2012.10.055

[12] Fountoulakis, I., et al. (2018) Twenty-Five Years of Spectral UV-B Measurements over Canada, Europe and Japan: Trends and Effects from Changes in Ozone, Aerosols, Clouds, and Surface Reflectivity. Comptes Rendus Geoscience, 350, 393-402. https://doi.org/10.1016/j.crte.2018.07.011

[13] Andrady, A.L., Pandey K.K. and Heikkila A.M. (2019) Interactive Effects of Solar UV Radiation and Climate Change on Material Damage. Photochemical \& Photobiological Sciences, 18, 804-825. https://doi.org/10.1039/C8PP90065E

[14] Elani, U.A. (2007) Distribution of Ultraviolet Solar Radiation at Riyadh Region, Saudi Arabia. Environmental Monitoring and Assessment, 124, 253-241. https://doi.org/10.1007/s10661-006-9221-x

[15] Martinez-Lozano, J.A., Tena F. and Utrillas M.P. (1996) Measurement and Analysis of Ultraviolet Solar Irradiation in Valencia, Spain. International Journal of Climatology, 16, 947-955. https://doi.org/10.1002/(SICI)1097-0088(199608)16:8<947::AID-JOC55>3.0.CO;2-O

[16] Elhadidy, M.A., Abdel-Nabi, D.Y. and Kruss, P.D. (1990) Ultraviolet Solar Radiation at Dhahran, Saudi Arabia. Solar Energy, 44, 315-319. https://doi.org/10.1016/0038-092X(90)90135-Y

[17] Foyo-Moreno, I., Vida, J. and Alados-Arboledas, L. (1999) A Simple All Weather Model to Estimate Ultraviolet Solar Radiation (290 - $385 \mathrm{~nm}$ ). Journal of Applied 
Meteorology and Climatology, 38, 1020-1025. https://doi.org/10.1175/1520-0450(1999)038<1020:ASAWMT>2.0.CO;2

[18] Feister, U. and Grasnick, K.H. (1992) Solar UV Radiation Measurements at Potsdam $\left(52^{\circ} 22 \mathrm{~N}, 13^{\circ} 5 \mathrm{E}\right)$. Solar Energy, 49, 541-548. https://doi.org/10.1016/0038-092X(92)90162-4

[19] Sadler, G.W. (1992) Ultraviolet Radiation at Edmonton, Alberta, Canada. Sol Energy, 49, 13-17. https://doi.org/10.1016/0038-092X(92)90121-P

[20] Bilbao, J., Roman, R., Yousif, C., Pérez-Burgos, A., Mateos, D. and de Miguel, A. (2015) Global, Diffuse, Beam and Ultraviolet Solar Irradiance Recorded in Malta and Atmospheric Component Influences under Cloudless Skies. Solar Energy, 121, 131-138. https://doi.org/10.1016/j.solener.2015.04.048

[21] Leal, S.S., Tiba, C. and Piacentini, R. (2011) Daily, UV Radiation Modeling with the Usage of Statistical Correlations and Artificial Neural Networks. Renewable Energy, 36, 3337-3344. https://doi.org/10.1016/j.renene.2011.05.007

[22] Al-Mostafa, Z., Elminir, H., Abulwfa, A., Al-Shehri, S., Alshehri, F., Al-Rougy, I. and Bazyad, A. (2015) Evaluation of Erythemal Ultraviolet Solar Radiation over Saudi Arabia. Solar Energy, 113, 258-271. https://doi.org/10.1016/j.solener.2015.01.010

[23] Bais, A.F., Bernhard, G., McKenzie, R.L., Aucamp, P.J., Young, P.J., Ilyas, M., Jockel, P., and Deushi, M. (2019) Ozone-Climate Interactions and Effects on Solar Ultraviolet Radiation. Photochemical \& Photobiological Sciences, 18, 602-640. https://doi.org/10.1039/C8PP90059K

[24] Yousif, C.Y., Oña, G. and Bilbao, J. (2013) Comparison of Solar Radiation in Marsaxlokk, Malta and Valladolid, Spain. Renewable Energy, 49, 203-206. https://doi.org/10.1016/j.renene.2012.01.031

[25] Akhlaghi, M., Radfard, M., Arfaeinia, H., Soleimani, M. and Fallahi, A. (2018) Ultraviolet Radiation Rate in Mashhad, Iran. Data in Brief, 19, 1086-1091. https://doi.org/10.1016/j.dib.2018.05.116

[26] El-Nouby, M. (2015) Determination of Daily Total Ultraviolet-B in a Subtropical Region (Upper Egypt): An Empirical Approach. Atmospheric Research, 153, 1-9. https://doi.org/10.1016/j.atmosres.2014.07.025

[27] Stammes, K., Tsay, S.C., Wiscombe, W.J. and Jayawerera, K. (1988) Numerically Stable Algorithm for Discrete-Ordinate-Method Radiative Transfer in Multiple Scattering and Emitting Layered Media. Applied Optics, 27, 2502-2509. https://doi.org/10.1364/AO.27.002502

[28] Escobedo, J.F., Gomes, E.N., Amauri, P., Oliveira, A.P. and Soares J. (2011) Ratios of UV, PAR and NIR Components to Global Solar Radiation Measured at Botucatu Site in Brazil. Renewable Energy, 36, 169-178. https://doi.org/10.1016/j.renene.2010.06.018

[29] Navntoft, L.C., Fernandez-Ibañez, P. and Garreta F. (2012) UV Solar Radiation on a Tilted and Horizontal Plane: Analysis and Comparison of 4 Years of Measurements. Solar Energy, 86, 307-318. https://doi.org/10.1016/j.solener.2011.10.004

[30] Jacovides, C.P., Boland, J., Rizou, D., Kaltsounides, N.A. and Theoharatos, G.A. (2012) School Students Participation in Monitoring Solar Radiation Components: Preliminary Results for UVB and UVA Solar Radiant Fluxes. Renewable Energy, 39, 367-374. https://doi.org/10.1016/j.renene.2011.08.037

[31] Koronakis, P.S., Sfantos, G.K., Paliatsos, A.G., Kaldellis, J.K., Garofalakis, J.E. and Koronaki, I.P. (2002) Interrelations of UV-Global/Global/Diffuse Solar Irradiance 
Components and UV-Global Attenuation on Air Pollution Episode Days in Athens, Greece. Atmospheric Environment, 36, 3173-3181. https://doi.org/10.1016/S1352-2310(02)00233-9

[32] Kudish, A.I. and Evseev, E.G. (2011) The Analysis of Solar UVB Radiation as a Function of Solar Global Radiation, Ozone Layer Thickness and Aerosol Optical Density. Renewable Energy, 36, 1854-1860. https://doi.org/10.1016/j.renene.2010.12.008

[33] Kudish, A.I. and Evseev, E.G. (2012) UVB Irradiance and Atmospheric Optical Depth at the Dead Sea Basin, Israel: Measurements and Modeling. Renewable Energy, 48, 344-349. https://doi.org/10.1016/j.renene.2012.05.014

[34] Porfirio, A.C.S., De Souza, J.L., Lyra, G.B. and Lemes, M.A.M. (2012) An Assessment of the Global UV Solar Radiation under Various Sky Conditions in $\mathrm{Ma}$ ceió-Northeastern Brazil. Energy, 44, 584-592.

https://doi.org/10.1016/j.energy.2012.05.042

[35] Downs, N., Parisi, A., Galligan, L., Turner, J., Amar, A., King, R., Ultra, F. and Bulter, H. (2016) Solar Radiation and the UV Index: An Application of Numerical Integration, Trigonometric Functions, Online Education and the Modelling Process. International Journal of Research in Education and Science, 2, 179-189.

[36] Charuchittipan, D., Choosri, P., Janjai, S., Buntoung, S., Nunez, M. and Thongrasmee, W.A. (2018) A Semi-Empirical Model for Estimating Diffuse Solar Near Infrared Radiation in Thailand Using Ground- and Satellite-Based Data for Mapping Applications. Solar Energy, 117, 175-183. https://doi.org/10.1016/j.renene.2017.10.045

[37] Ye, Q., Chen, M. and Cai, W. (2019) Numerically Investigating a Wide-Angle Polarization-Independent Ultrabroadband Solar Selective Absorber for High-Efficiency Solar Thermal Energy Conversion. Solar Energy, 184, 489-496. https://doi.org/10.1016/j.solener.2019.04.037

[38] Prakash, J.P., Stenchikov, G., Kalenderski, S., Osipov, S. and Bangalath, H. (2015) The Impact of Dust Storms on the Arabian Peninsula and the Red Sea. Atmospheric Chemistry and Physics, 15, 199-222. https://doi.org/10.5194/acp-15-199-2015

[39] Sabbaha, I., Léonb, J.-F., Sorribasc, M., Guinotb, B., Córdoba-Jaboneroc, C., de Souzad, A. and Al Sharifie, F. (2018) Dust and Dust Storms over Kuwait: Ground-Based and Satellite Observations. Journal of Atmospheric and Solar-Terrestrial Physics, 179, 105-113. https://doi.org/10.1016/j.jastp.2018.06.006 